\title{
Aquellos antiguos edificios. Acercamiento arqueológico a la arquitectura prehispánica tardía de Caspana ${ }^{1}$
}

\author{
LEONOR ADÁN A. ${ }^{2}$
}

\section{RESUMEN}

Este trabajo expone la caracterización arquitectónica y la descripción de las excavaciones practicadas en sitios arqueológicos de los períodos Intermedio Tardío y Tardío de la localidad de Caspana, los cuales constituyen el objeto de estudio de esta investigación. Se trata de dos asentamientos de la población local, la Aldea Talikuna y la Estancia Mulorojte, y tres instalaciones incaicas de distinta naturaleza, Cerro Verde, Incahuasi-Inca y Vega Salada. A partir de ellos se analiza el papel de la arquitectura como materialidad para el dominio, apropiación e integración de los grupos humanos y los territorios de esta geografía, a la esfera política del Estado inca o Tawantinsuyu.

\section{ABSTRACT}

This paper presents an architectural characterization and a brief description of the excavations made at the archaeological sites of the Late and Late Intermediate periods from Caspana locality, which constitutes the study matter at the current research. They are two local settlements, the Aldea Talikuna and the Estancia Mulorojte, and three different nature inca instalations, Cerro Verde, Incahuasi-Inca y Vega Salada. We analize the architecture role like a materiality for the domain, appropriation and integration of people and territories from this geography to the inca state or Tawantinsuyu political sphere.

\footnotetext{
1 Proyectos FONDECYT 1970528 y 1000148.

2 Universidad Austral de Chile. Museo Histórico Valdivia. Email: ladan@uach.cl
}

\section{Introducción}

La arquitectura que caracteriza los sitios de los períodos tardíos de Caspana constituye, junto con la alfarería, parte de la producción cultural más sensible para la investigación arqueológica de dichos momentos. La opción metodológica que aplicamos en la ejecución de esta investigación, consideró el análisis de diferentes materialidades que acompañaron a los antiguos habitantes de estos territorios. La posibilidad de vislumbrar el fenómeno de expansión del Tawantinsuyu hacia las tierras altas del río Loa y las consecuentes tensiones que ello debió generar en la población local quedó expresada en diversos materiales, documentos y discursividades; que razón por la cual, pensamos que debíamos efectuar un estudio integrador, que entrecruzara los distintos datos y sus lecturas.

Los trabajos arqueológicos sobre los períodos tardíos en el río Salado, afluente del Loa, han desarrollado de manera importante el análisis de la arquitectura aportando valiosos resultados. Entre ellos la definición de una metodología para la caracterización de la arquitectura, que aquí empleamos (Castro et al. 1993). La aproximación al estudio de la funcionalidad de los recintos por su parte, considera esta descripción básica, además de antecedentes etnoarqueológicos e información depositacional que, en este caso, exponemos brevemente, consecuente con una metodología que se ha sistematizado previamente (Adán 1995 y 1996).

Cinco fueron los asentamientos estudiados. Tres de ellos corresponden a la categoría que hemos denominado "exclusivos incaicos": Cerro Verde, 
Incahuasi-Inca y Vega Salada. Los otros dos yacimientos constituyen asentamientos que inicialmente hemos catalogado como "poblados locales", correspondientes a la Aldea Talikuna, y Estancia Mulorojte. Un caso aparte es el del sitio Cementerio de los Abuelos, cuya arquitectura y estudio arqueológico son materia de otro trabajo (Ayala et al. en este volumen). ${ }^{3}$

En el marco de la problemática que orienta esta investigación, el interés por profundizar el análisis de la arquitectura, se debe a que indudablemente ella constituye un elemento privilegiado del Estado incaico para organizar su mundo, apropiar territorios, señalar su dominio, e integrar poblaciones, cuestión que han destacado numerosos como connotados investigadores considerando las características de esta materialidad y enfatizando diversos aspectos (Agurto 1987, Gasparini y Margolies 1980, Hyslop 1990 y 1993, Raffino 1981, entre otros). El Loa no escapa a esta situación, del todo evidente en sitios arqueológicos como el Pukara de Turi, con su imponente kallanka y cancha, irrumpiendo en el espacio edificado (Cornejo 1995 y en este volumen, Gallardo et al. 1995), que corrobora la reflexión de Hyslop (1993: 343) en el sentido de evaluar la aparente marginalidad de algunos territorios (Adán y Uribe 1999).

Durante el Período Intermedio Tardío, en las tierras altas del Loa la arquitectura constituye un ítem de su cultura material altamente significativo en términos funcionales y simbólicos, por lo cual resulta necesario comprender el sustrato sobre el que se asentó el Tawantinsuyu. El "construir para habitar" se articula como una noción orientadora de las estrategias que las poblaciones locales desarrollaron para vivir y morir en este territorio. La historia cultural de la localidad (Adán y Uribe 1995, Uribe y Adán 1995), demuestra que una importante situación ocurrida en las tierras altas durante los períodos tardíos, y que de alguna manera revirtió los procesos acontecidos en épocas previas donde los sectores de oasis más bajos actuaron como un polo de gravitación cultural, como es el caso de San Pedro de Atacama, fue la disposición y conocimiento de esta tecnología, la arquitectura de tierras altas. Ella permitió habitar las quebradas y hacer productivos espacios antes "casi" deshabitados. En este contexto, situándose en Caspana, la expresión de la expansión del Tawantinsuyu a través de la arquitectura, debió generar en las poblaciones locales un fuerte impacto y complejas reorganizaciones de su geografía política y cultural (Adán y Uribe 1999).

\section{La construcción del espacio local}

El sitio Aldea Talikuna puede entenderse como un asentamiento "permanente" de la población local, ubicado en la quebrada homónima a una distancia de $1,5 \mathrm{~km}$ aproximadamente del pueblo antiguo de Caspana y a una altura de $3.250 \mathrm{~m} . \mathrm{snm}$ (Figura 1). ${ }^{4}$ Las fechas que hemos obtenido, $1160 \pm 90$ DC (UCTL 722), $1305 \pm 70$ DC (UCTL 723), y $1465 \pm 60$ DC (UCTL 724), indican que el poblado fue ocupado en momentos clásicos del Período Intermedio Tardío.

En una primera observación destaca el lugar donde se emplaza la aldea, el talud de la quebrada de Talikuna. En consecuencia, su construcción requirió del conocimiento y manejo de técnicas constructivas específicas que permiten habitar las quebradas, creando sectores planos por medio de aterrazamientos y terraplenes. La proximidad de los espacios domésticos con las áreas de producción, en especial agrícola, es un rasgo distintivo de Talikuna que comparte con otros asentamientos locales y también con los sitios incaicos, pero de una manera diferente.

El asentamiento ha sido descrito como compuesto por tres sectores edificados (Le Paige 1958), destacando la ausencia de un muro perimetral. El primero de ellos es el sector bajo donde se ubican las terrazas de cultivo, que se extienden por largos kilómetros en la ladera de exposición norte del valle, junto al complejo sistema agrohidraúlico que atraviesa la aldea. Las características del sitio

\footnotetext{
3 Debido al actual estado de conservación del sitio y significancia para la comunidad indígena de la localidad, no fue posible aplicar los mismos criterios de trabajo que en los otros sitios, es decir, fichaje arquitectónico de las estructuras, levantamiento taquímetrico, recolección superficial, sondeos y excavaciones, utilizando otra metodología.

4 Trabajos previos conocidos son los de Barón (1979), Le Paige (1958) y Núñez (1965)
} 


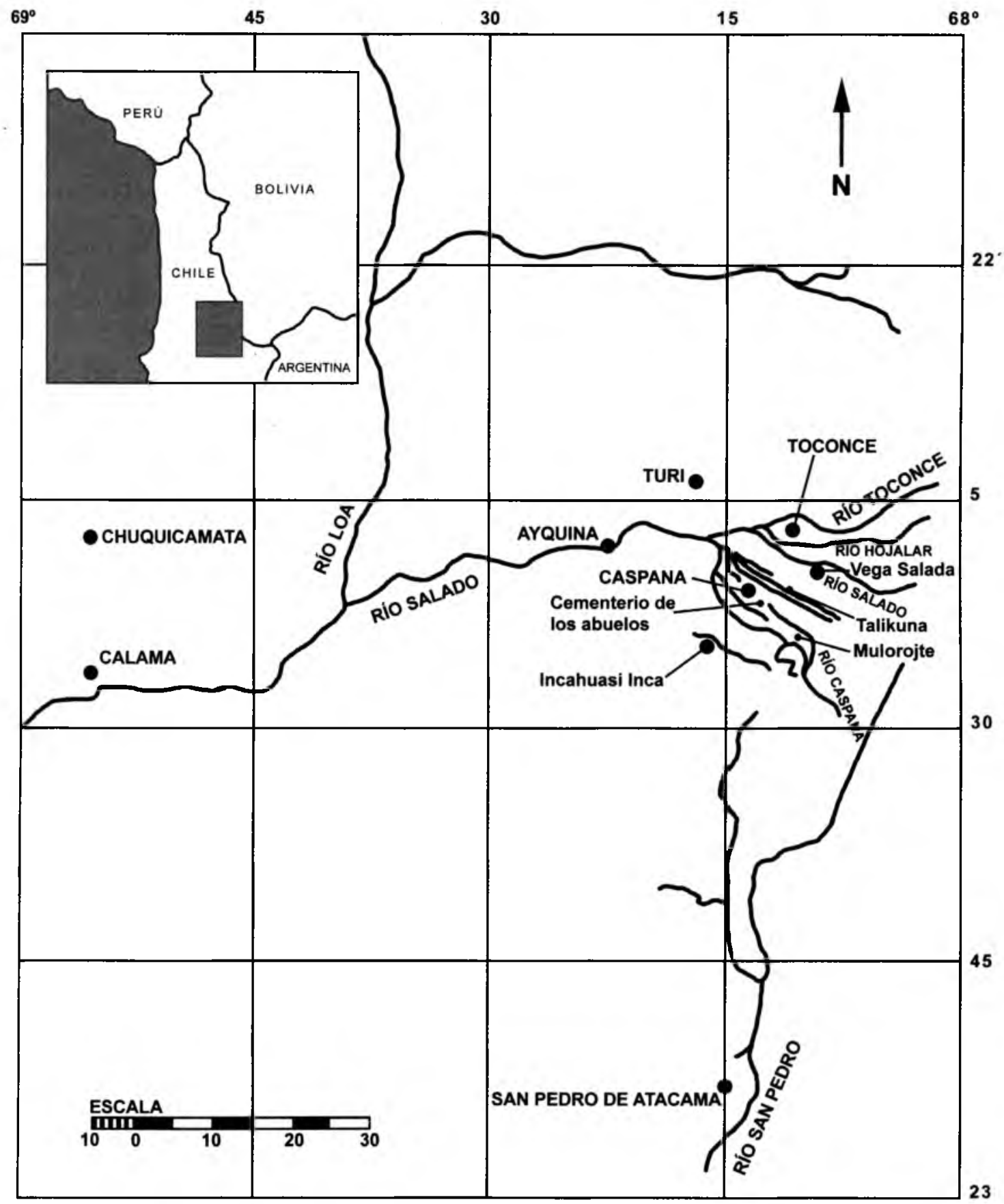

Figura 1. Mapa de ubicación de la localidad de Caspana y de los sitios arqueológicos estudiados 
hacen evidente el marcado énfasis agrícola del asentamiento, en el cual no existen evidencias arquitectónicas de una importante actividad pastoril, sin perjuicio de lo cual ello pueda estar representado en otros sectores como las mesas entre quebradas, o bien sus pobladores haber participado en la ocupación del Pukara de Turi, asentamiento de marcado carácter ganadero.

Inmediatamente sobre el sector destinado a la agricultura, separado por el canal principal del sistema de regadío se ubica el sector residencial o habitacional, donde destacan conjuntos de planta subrectangular y estructuras de patrón constructivo tipo chullpa (Aldunate y Castro 1981, Ayala 2000). Los paramentos fueron construidos con piedras y en su mayoría son de hilada simple. Respecto de la disposición general del sector doméstico, se observa una mayor concentración en la mitad oriental o aguas arriba del sitio, donde se localizan conjuntos aglutinados y compactos, formados por estructuras rectangulares e irregulares. Por su parte, la mitad aguas abajo exhibe un patrón más disperso con un mayor número de estructuras de mayores dimensiones. Por último, en el sector más alto se identificaron construcciones adosadas a grandes bloques pétreos similares a los del Cementerio de los Abuelos, algunas de las cuales corresponderían a entierros en abrigos rocosos (Ayala et al. en este volumen).

Al igual que en otros asentamientos contemporáneos de la localidad y de otras partes del mundo andino, sobretodo si se compara con la arquitectura inca, en Talikuna se nota un crecimiento espontáneo, sin una planificación inicial, tal como se ocupan hoy los poblados locales (Agurto 1987). Sin embargo, ésto no significa que no existieran especialistas comprometidos en su construcción. Como se ha señalado, el hacer habitable esta quebrada y en general las quebradas altas de esta región, requiere del conocimiento tecnológico adecuado y que en algunos niveles debió demandar la existencia de expertos en arquitectura e hidráulica.

Entre los 151 recintos que componen el sitio (Figura 2), se observa que en su mayoría corresponden a construcciones de planta rectangular y subrectangular, sin presentar un claro trazado ortogonal. Les siguen los recintos irregulares sin ángulos, los de planta cuadrada, y con muy bajas frecuencias las plantas circulares o subcirculares, las elipsoidales y las ovoides. Una adscripción preliminar de la funcionalidad a partir de los rasgos arquitectónicos, señala que los recintos de planta rectangular y subrectangular involucran estructuras habitacionales probablemente techadas, espacios domésticos exteriores, aterrazamientos, espacios entre-recintos, y construcciones tipo chullpa. Los recintos de planta irregular probablemente corresponden a espacios exteriores y entre-recintos, recintos habitacionales y corrales. Las formas cuadradas incluyen mayoritariamente construcciones tipo chullpa, como también ocurre con las plantas circulares o subcirculares y elipsoidales.

Las superficies oscilan entre los $1,7 \mathrm{~m}^{2}$ hasta los $88,7 \mathrm{~m}^{2}$, concentrándose más de la mitad de las estructuras entre los $7,5 \mathrm{y} \operatorname{los} 38 \mathrm{~m}^{2}$. Las menores superficies se relacionan con aquellas de patrón constructivo tipo chullpa, mientras en los recintos de planta rectangular irregular se presenta una amplia variación, aunque en ningún caso de menor superficie que $10 \mathrm{~m}^{2}$, lo que reforzaría la tesis del carácter mayoritariamente doméstico de esta forma de planta.

Pese a constituir la Aldea de Talikuna el mayor asentamiento que trabajamos, tanto por la superficie que compromete como por el número de construcciones, se trata de un sitio de dimensiones regulares, en el que se distinguen 19 conglomerados conformados por recintos que comparten muros, los que a juzgar por su disposición se traducirían en cinco conjuntos o unidades domésticas, que deben concebirse en un sentido diacrónico para lograr una mejor comprensión de la ocupación de la aldea. También resulta fundamental concebir el asentamiento de Talikuna como formando parte de una red de asentamientos habitados por la población local, los que seguramente tienen cierto control productivo sobre la quebrada que habitan. En una jerarquía de sitios, pareciera ser Caspana mismo, considerando el importante cementerio arqueológico contiguo y el camino que lo conecta con el sitio incaico de Cerro Verde, una localidad de mayor interés para el Tawantinsuyu, dejando relativamente libre la ocupación de este asentamiento menor.

Talikuna es la aldea local del Período Intermedio 


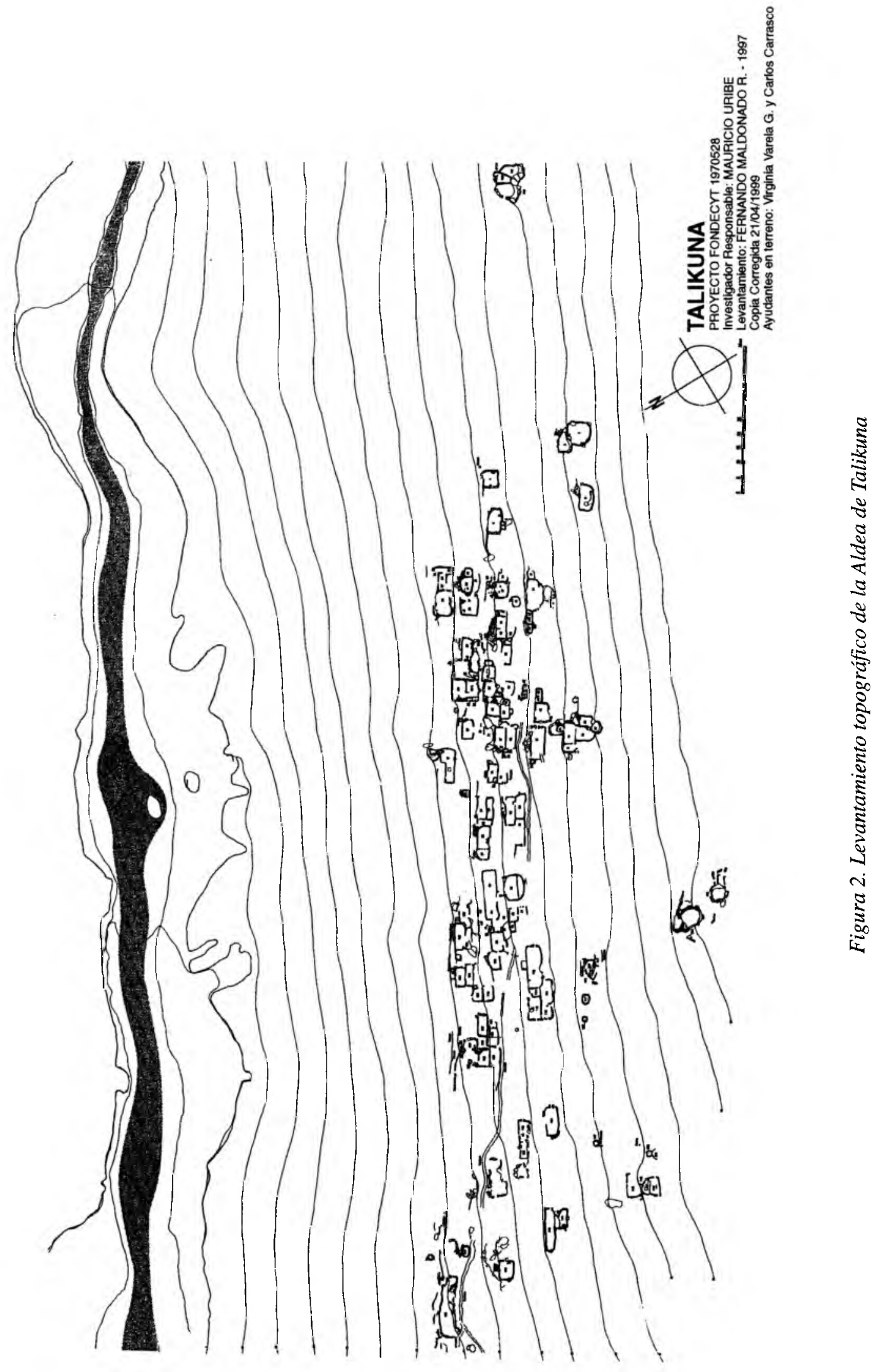


Tardío que conocemos hoy en la localidad de Caspana, razón por la cual los resultados de su excavación han sido fundamentales para comprender la historia y organización interna del asentamiento. Desde una perspectiva más amplia, nos interesaba comprender cómo era una aldea local para develar la forma en que el dominio inca afectaba estos espacios domésticos. De tal manera, las excavaciones practicadas en 14 recintos correspondientes a un $10 \%$ de las estructuras, se orientaron a comprender la ocupación del sitio desde una perspectiva diacrónica, junto con las características funcionales de los barrios reconocidos.

En el sector SE de la aldea se excavaron los recintos $12,14,16,22,23,28$. En este conjunto los recintos 22 y 23 ocupan un lugar central, destacando por su carácter doméstico y rasgos arquitectónicos particulares. El recinto 23 presenta una planta rectangular irregular con una superficie de $16,56 \mathrm{~m}^{2}$. en su muro superior conserva una hornacina $a^{5}$ y en superficie instrumentos de molienda y una "cajita" construida en piedra laja. ${ }^{6}$ El depósito registró, amparado hacia el muro sur, la presencia de un fogón acompañado de desechos líticos, cerámica fragmentada, restos óseos y restos vegetales como chañar y zuros de maíz, mientras que en otro sector de la excavación se observó una pequeña cavidad rellena con basura, que podría corresponder a la limpieza del fogón.

La estructura 23 contiene al recinto 22 , de planta cuadrada y superficie de $4,05 \mathrm{~m}^{2}$, el que conserva un vano de $98 \mathrm{~cm}$ de altura, con su dintel de piedra. Presenta una compleja estratigrafía en la que se suceden eventos de quemas entremezclados con restos vegetales, óseos y alfareros. Probablemente se trata de un pequeño depósito con un área de cocina. Constituye en definitiva una unidad compuesta de carácter doméstico, formando un patrón "recinto habitacional con estructura asociada a modo de depósito", integrando un conjunto mayor a modo de barrio.

Los vanos de este conjunto, caracterizan el comportamiento en aquellas estructuras rectangulares o subrectangulares, ubicándose en los muros de menor largo del rectángulo, el que se corresponde con la pared transversal de los recintos tomando como referencia el sentido de la quebrada. ${ }^{\text {? }}$

Por su parte, el recinto 28 , de planta rectangular, con una superficie de $40 \mathrm{~m}^{2}$, constituye otro espacio residencial pero con un poyo adosado al muro Sur, mientras que en sus paramentos igualmente se presenta una hornacina. Aquí se registró un fogón claramente delimitado por piedras. Sus características indican que correspondería a una unidad doméstica de amplias dimensiones, probablemente sin techo como una "ramada." En cambio, las estructuras 12 y 14 forman parte de un conjunto chullpario ${ }^{8}$ triple (Ayala 2000), en tanto el recinto 16 constituye un espacio entre-recintos que fue usado como basural.

En el sector centro-Este de la aldea, próximo al siguiente, se excavó el recinto 45 , de planta rectangular y grandes dimensiones, $31,24 \mathrm{~m}^{2}$. Esta estructura, arquitectónicamente, ejemplifica un patrón definido por una "estructura tipo chullpa adosado a un recinto mayor a modo de pequeña plaza asociada." Su excavación prácticamente no aportó material cultural, lo que evidencia que allí no se depositaron basuras, aunque más bien parece corresponder a un espacio despejado de desechos, como aquellos utilizados para fines ceremoniales y públicos (Adán 1996).

También en este sector se excavaron los recintos 36,51 y 52 los cuales forman parte de un segundo conglomerado de importancia en el sector central. El recinto 52 , de planta rectangular y $20,65 \mathrm{~m}^{2}$, con el 51 , que es cuadrado de $4 \mathrm{~m}^{2}$, reproducen idéntico patrón arquitectónico "depósito-habitación", definido por los recintos 22 y 23 . Sin embargo, en este caso el recinto 51 corresponde a

\footnotetext{
5 Se registraron nueve recintos con homacinas.

6 A nivel superficial se observó este rasgo en dos estructuras. Trabajos previos realizados en el Pukara de Turi (Adán 1996) indican que las cajitas líticas son frecuentes en espacios domésticos a modo de ofrenda o waki fundacional.

7 En los sitios incaicos, en cambio, los vanos siempre se encontrarán en los muros largos del rectángulo, orientados hacia el Este.

8 Un aspecto notable es la presencia de 29 estructuras con patrón constructivo tipo chullpa. Ellas presentan una superficie entre los 1,69 y $8,67 \mathrm{~m}^{2}$, concentrándose entre los 1,69 y $\operatorname{los} 4,37 \mathrm{~m}^{2}$. Entre estas estructuras las plantas mayoritariamente son cuadradas y rectangulares, registrándose ovoidales, elipsoidales y subcirculares.
} 
una estructura tipo chullpa, con su vano característico y parte del techo aún conservado, conformado por grandes piedras lajas. En cualquier caso, se trata de una estructura mayor que comunica a una menor a través de vanos entre recintos edificados. El material cultural y las características depositacionales de la unidad 52 son típicamente domésticas. En el caso de la 51, lamentablemente, el contex to se encontró sumamente disturbado.

En el caso del recinto 36, de planta irregular y 9,6 $\mathrm{m}^{2}$ de superficie, se registraron algunos lentes de ceniza dispersos. Sin embargo, los antecedentes no son muy claros para aseverar funciones residenciales.

En el sector centro-Oeste se excavaron los recintos 86 y 98 , los que forman parte de un conjunto mayor. Destaca el recinto 86 , de planta rectangular y una superficie de $17,27 \mathrm{~m}^{2}$, el cual tanto por sus características arquitectónicas como depositacionales es indicativo de espacios domésticos. Cubriendo gran parte de la excavación, se encontró un fogón o área de fogón, adosado al muro sur o superior. En éste se encontraron abundantes restos culturales, principalmente cerámica, huesos quemados y dos piezas líticas excepcionales. Uno de ellos pareciera ser a un "dado" del juego incaico llamado pichica, tal cual es descrito por Gentile (1997). Seguramente estos materiales pasaron a formar parte del fogón debido a la consistencia suelta que caracteriza a este tipo de matriz. En el caso del recinto 98, de planta rectangular y $25,2 \mathrm{~m}^{2}$, los antecedentes fueron insuficientes para asignar alguna funcionalidad.

Por último, se excavó en el sector alto-Oeste de la aldea, el exterior de una pequeña chullpa de 4,32 $\mathrm{m}^{2}$ de planta rectangular, adscrita al tipo aislada simple (Ayala 2000). El depósito documenta la presencia de eventos de quemas y arcilla quemada, registrada en otras estructuras de estas características que hacen suponer prácticas religiosas (Aldunate y Castro 1981).

El sitio Mulorojte correspondería a una estancia arqueológica. Se localiza en los faldeos nororientales de los Morros del Cablor, a una altura de $3.800 \mathrm{~m} . \mathrm{snm}$, en un pequeño anfiteatro donde se forma la quebrada que da nombre al sitio (Figura 1).
Por su altitud, el área presenta un alto potencial forrajero hasta la actualidad empleado por los pastores, e importantes aguas lluvia durante el verano lo que permitiría el desarrollo de una agricultura de secano con cultivos resistentes a la altura y al frío. De hecho, entre sus estructuras se cuentan corrales y en superficie se han encontrado morteros y desechos de palas líticas. El único fechado absoluto realizado en Mulorojte nos indica una antigüedad de $1240 \pm 80$ DC (UCTL 725), el que marca sólo un momento de su ocupación, contemporáneo a aquellos más tempranos de Talikuna.

A una distancia de $3 \mathrm{~km}$ se encuentran las vegas del Cablor, Chita y la laguna de Coyer, desde donde nace el río Caspana y se forma la quebrada con el mismo nombre. Los cerros Cablor y Chita son muy importantes para los caspaneños, pues se trata de sus mallku o cumbres tutelares (Sipitare tata y Sipitare mama). Anualmente realizan una ceremonia en la cual depositan agua de mar sobre su cima. Su importancia es tanto económica como religiosa. De hecho, una de las rutas de ascenso transita por el sitio arqueológico.

Al igual que Talikuna, Mulorojte se levanta sobre un plano inclinado, edificado sobre un considerable sistema de aterrazamientos en el cual se observan estructuras de planta rectangular de tamaños variables y muros de hilada simple que se organizan básicamente en tres sectores, algunos de ellos también formando especies de barrios ( $\mathrm{Fi}$ gura 3).

En el sector bajo, cortado por el actual camino de vehículos, se identifica un patrón arquitectónico configurado por la presencia de una serie de recintos de grandes dimensiones, a modo de corrales, con estructuras menores asociadas en su interior. En algunos casos dichas construcciones parecen corresponder a "chiqueros", como el conjunto formado por los recintos 13 y $15 .{ }^{9} \mathrm{En}$ otros, en cambio constituirían unidades habitacionales

\footnotetext{
9 Etnográficamente se designa como chiquero a una estructura de pequeñas dimensiones, adosado a un corral, el cual es usado para mantener separados del resto del ganado a los animales pequeños y a las hembras parturientas. Presentan un pequeño vano de forma cuadrada a nivel de suelo (Adán 1996).
} 


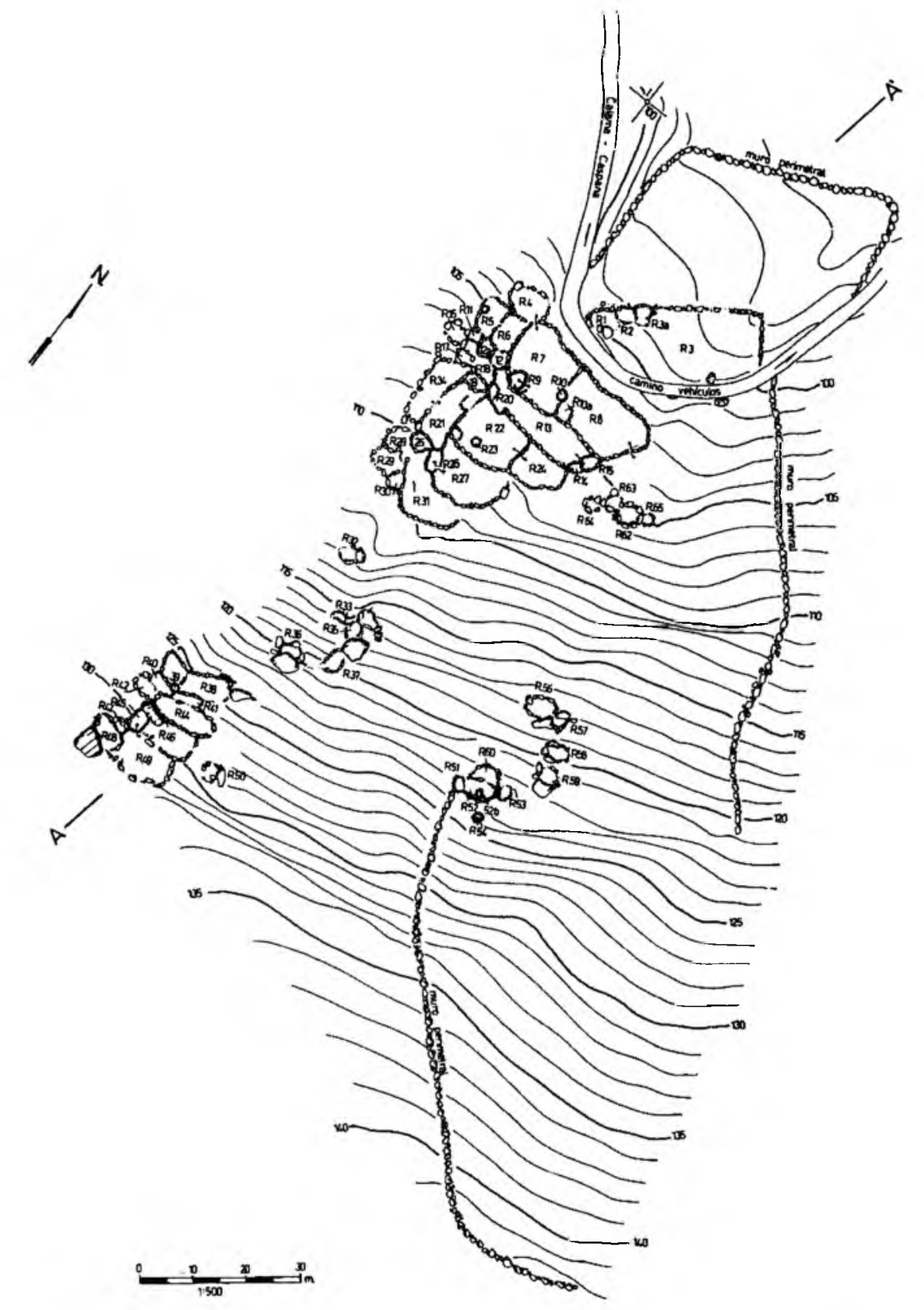

SITIO: MULOROJTE / CASPANA. COMUNA CALAMA, II REGION. Fondecyt: 1970528 Sept. 1998

COORD. PROYECTO: M. URIBE R.

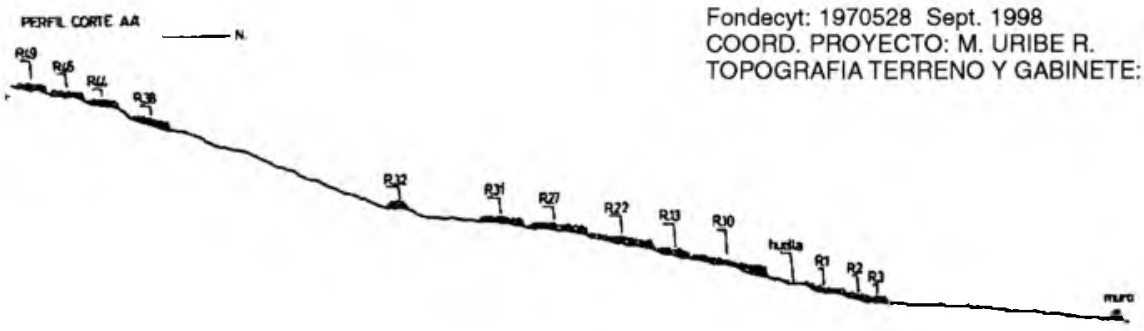

Figura 3. Levantamiento topográfico de Estancia Mulorojte 
como es el caso del conjunto 7-9, y 26-27. Los muros predominantes son simples y rústicos aunque se encuentran algunos dobles. Algunos rasgos interesantes que se detectan en este sector es la presencia de una hornacina, poyos y la presencia de "cajitas" levantadas con piedra en el piso. Destaca en este sector la presencia de una estructura tipo chullpa al centro de un gran recinto numerado 22 y de un muro perimetral que cerca el asentamiento por el norte, gran parte del este, y hasta toparse con el vértice noroeste del recinto 7.

La organización y estructura de este primer sector parece ser el resultado de diversos eventos constructivos con el resultado de sucesivas modificaciones desde el Intermedio Tardío cuando comenzó a edificarse, hasta ahora.

El segundo sector en la parte alta del sitio, se ubica inmediatamente sobre el primer conjunto. Está formado por cuatro niveles de aterrazamientos, correspondientes a los recintos $38,41,44$, y 46. El primero de ellos, de gran amplitud, es utilizado hoy en día como sendero. En este sector, al igual que en el anterior se observan asociadas una estructura de grandes dimensiones adosada a recintos menores de planta subrectangular, de mayor carácter habitacional, como es el caso de los recintos 42 y 44 .

Por último se encuentra el sector alto oriental, e] que en terreno se observa confuso, porque está compuesto en la actualidad por un conjunto de recintos pobremente definidos y donde no existen las grandes estructuras que hemos descrito para el sector bajo y alto. Más precisamente, está formado por tres conglomerados. El primero de ellos es el que se localiza bajo o al amparo de bloques rocosos, donde se encuentran aterrazamientos de forma irregular asociados a probables trojas, que serían las estructuras $33,34,35,36$ y 37 . El segundo está representado por el conglomerado alto, muy destruido, con la presencia de algunas estructuras subrectangulares como la 51, y la notable presencia de tres estructuras tipo chullpa, de factura curiosa, y de una pequeña construcción de patrón en U, formada por lajas de no más de 50 $\mathrm{cm}$ de altura. Finalmente se encuentran las estructuras irregulares, a modo de plataformas adosadas a bloques, de construcción más descuidada que pensamos podrían corresponder a períodos más tempranos. Inclusive existirían en el resto del asentamiento otras estructuras con un "aire" temprano como ocurre con el recinto 30 en el sector bajo. El componente alfarero temprano (Adán y Uribe 1995) está documentado en este último sector y, en general, se observan en el sitio morteros y material lítico de filiación arcaico-formativa.

Debido al estado actual del yacimiento, por los procesos de formación que lo afectaron, la planta original es bastante confusa. En muchos casos la arquitectura está mal conservada o francamente deteriorada. Estas razones no permitieron sugerir mayores hipótesis funcionales. Se observan probables estructuras usadas como recintos habitacionales, corrales, aterrazamientos y plataformas, así como depósitos y estructuras con patrón constructivo tipo chullpa.

En términos generales, las excavaciones practicadas se orientaron a obtener una mayor comprensión de esta clase de asentamientos presentes en el Intermedio Tardío, las estancias, como asimismo la relación existente entre éstos y aquellos más permanentes. Particularmente, y pese a las dificultades del registro, lo confuso de la planta y por la sucesiva reocupación del sitio, nos interesaba caracterizar los diferentes tipos de recintos de acuerdo a sus características arquitectónicas-funcionales y definir la forma en que se manifestaba la presencia incaica. Para ello se excavaron cuatro estructuras, lo que se suma a sondeos que realizáramos previamente.

El recinto 13, de planta irregular y una superficie de $164,25 \mathrm{~m}^{2}$, ejemplifica aquellos amplios espacios amurallados asociados a recintos menores. $\mathrm{La}$ densidad de los materiales recuperados es indicativa de un espacio pobre en depositación, comportamiento que igualmente habíamos detectado en recintos similares del Pukara de Turi (Adán 1995 y 1996). Un segundo recinto excavado, fue el 36, el cual arquitectónicamente se definía como un depósito o troja bajo bloque rocoso. Su planta es de forma rectangular, con una superficie de 9,89 $\mathrm{m}^{2} \mathrm{y}$ en su parte anterior se define una pequeña terraza que lo contiene. La excavación realizada en el exterior indica un depósito sumamente débil en material cerámico o lítico, aunque con una recurrente presencia de sectores con ceniza y tierra quemada, documentando la conducta de efectuar 
quemas, a modo de ceremonias, vinculadas a aquellos recintos usados para conservar (Adán 1995 y 1996). Por su parte, la estructura 45 corresponde al tipo "recinto menor integrado a un explazo mayor". Se trata de una construcción de planta rectangular, con una superficie de $12,48 \mathrm{~m}^{2}$ y parte de sus muros de hilada doble, aunque de factura tosca. El recinto presenta una estratigrafía compleja, afectada por numerosos bloques de piedra, los cuales pensamos corresponderían a derrumbes. Con todo, es posible identificar un nivel característico de ocupación doméstica con presencia de alfarería, restos óseos y pequeños carboncillos asociados a lentes de ceniza difusos. Un aspecto que reitera esta estructura, a diferencia de lo que ocurre con Talikuna, es la escasa depositación registrada en el sitio, la cual probablemente se deba a su carácter estanciero y al continuo reciclaje que tiene lugar en estos espacios atendiendo a la necesidad de optimizar los recursos materiales disponibles. Por último, en el sector oriental alto se excavó en el interior de una estructura de planta irregular, cercana a otra de patrón constructivo tipo chullpa. Presenta una superficie de $72,61 \mathrm{~m}^{2}$. De acuerdo a su escasa depositación no es posible sugerir una funcionalidad para la estructura.

\section{Los edificios del Tawantinsuyu}

"It is impossible to examine a single edifice of the Incas attentively without recognizing the same type in all the rest that exist throughout the Andes, extending over hundred leagues from one thousand to four thousand meters above sea level. It seems as if a single architect built this great number of monuments." (Alexander von Humboldt 1810, en Gasparini y Margolies 1980: 320).

El sitio incaico de mayor importancia ubicado en la localidad es Cerro Verde. Este se emplaza sobre la explanada del cerro del mismo nombre, a unos tres kilómetros del pueblo de Caspana, en la confluencia misma del río Curte con el río Caspana, sobre los 3.140 m.snm (Figura 1). Cerámica Yavi-La Paya proveniente del recinto 46 fue fechada en 1485 DC (UCTL 1190), en tanto, material de una sepultura en alero rocoso localizado en las inmediaciones del asentamiento fue datado en 1575 DC (UCTL 1191).

A diferencia de lo que ocurre con los sitios habi- tacionales de la población local, Cerro Verde se construyó en un plano a modo de meseta que permite la correcta reproducción del trazado ortogonal que caracteriza la unidad básica de las construcciones incaicas, sin constituir, obviamente, la única razón para su emplazamiento. Desde el punto de vista de la selección del paisaje y la construcción de un espacio cultural el lugar del asentamiento tiene igualmente relación con la confluencia de las quebradas Curte y Seca con la del Caspana, la cual se domina desde el asentamiento. Además el sector tiene un promontorio natural, lo suficientemente alto para permitir la visión de los cerros y volcanes que tutelan la región en todas sus direcciones, los caminos que cruzan las planicies y las vegas de Turi donde se localiza el otro importante sitio de la población local fuertemente intervenido por el Tawantinsuyu.

En este sentido, el asentamiento se entiende como formando parte de una red de instalaciones incaicas, tanto a nivel de la región, subregión como de la localidad, por tal razón, junto con Turi e Incahuasi-Inca se orientan en un eje norte-sur evidentemente vinculado a la red vial (Cornejo 1994, Varela en este volumen). Asimismo, y en cuanto al carácter monumental que adquiere en la región, el sitio expresa por parte de sus constructores una clara intención de visibilidad, amparado en el Cerro Verde, declarando uno de sus fundamentales intereses en la región, como fue la producción minera. Impone una arquitectura a un nivel macro denotando la construcción de una geografía política y cultural de la que no es posible escape vista alguna (Criado 1995). Junto con esta materialidad de obviedad traslucida, su estrategia de dominio utiliza igualmente otra clase de expresiones, como es el caso del arte rupestre presente en las inmediaciones del sitio que claramente se vinculan al Horizonte Tardío (Vilches y Uribe en este volumen). Otra atenta consideración que refleja el asentamiento, es el juego proximidad-distancia que establece con las áreas productivas cercanas, que como hemos señalado es otro rasgo en la manera de habitar estos territorios que lo diferencia de las aldeas locales. Así tanto las actividades de minería como agrícolas se encuentran documentadas, asociadas a este centro, sin llegar a afectar la construcción del plano. Por último, la selección de lugares ocupados previamente por poblaciones de las Tradiciones Tempranas (Adán y Uribe 


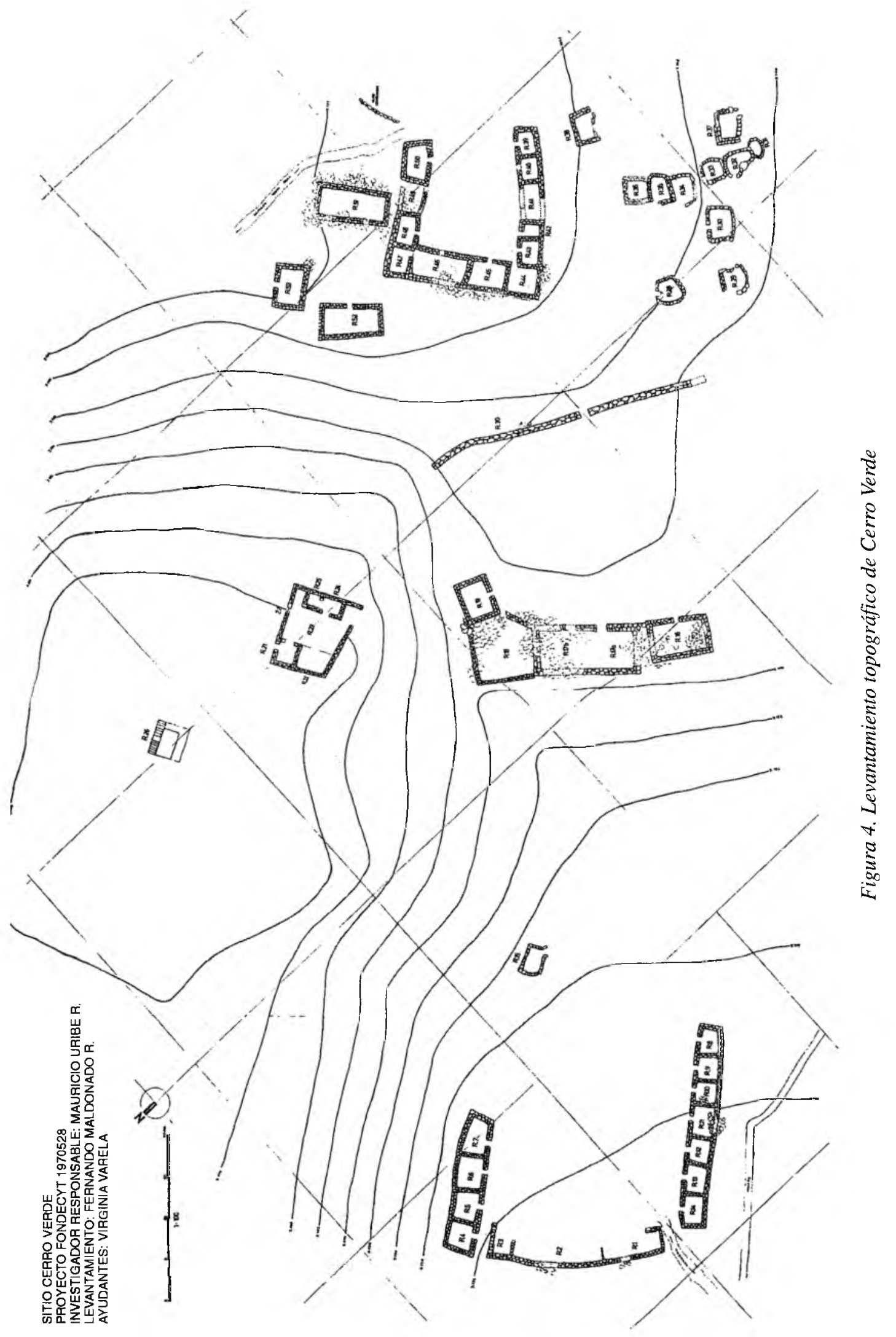


1995), es también una particular recurrencia que acompaña al emplazamiento del Tawantinsuyu en la localidad, y que en Cerro Verde es evidente a través del arte rupestre (Vilches y Uribe en este volumen). Se habitan los espacios "arqueológicos" de las poblaciones del Intermedio Tardío, lo que puede deberse exclusivamente a razones prácticas o bien a delicados procesos de exhibición de poder en los lugares de los antepasados (Uribe $e t$ al. 2000).

Esta instalación incaica se compone de 55 estructuras y plazas o patios de importantes dimensiones. Se aprecia claramente la aplicación de un trazado planificado, a través de una notoria regularidad y clara definición de los espacios edificados como de las vías de circulación (Figura 4). Una arquitectura con cuatro importantes explazos que enfatiza el carácter público. Ello da cuenta de un urbanismo planificado (Agurto 1987), el que requirió la participación de especialistas que conocían a cabalidad la arquitectura imperial.

Se reconocen tres sectores de edificación, todos ellos de factura tardía. El primero de ellos es el sector alto que se emplaza sobre un promontorio rocoso donde se levanta el ushnu o "plataforma piramidal", de planta rectangular y $15,40 \mathrm{~m}^{2}$, construido con piedra canteada, con escalas laterales y muros enlucidos con barro. En sus cercanías, sobre el mismo promontorio, se encuentra una estructura residencial compleja, definida por un muro perimetral con múltiples divisiones internas. La habitación interna fue edificada con muros de hilada doble, sus paredes también parecen haber presentado revoque y aún conserva un poyo exterior. En su interior se distingue lo que fuera un depósito con subdivisiones. Algunas cajas de piedra laja se levantan igualmente en este sector alto. Muy probablemente el uso de este conjunto estuvo vinculado a la función pública de este espacio, en el que el ushnu juega un rol fundamental. El segundo sector o bajo, veinte metros más abajo, se organiza en torno a conjuntos residenciales de patrón en $\mathrm{U}$, orientados hacia el E, y separados por un muro doble que segrega los subsectores poniente y oriental. En el sector bajo-poniente se identifican dos grandes estructuras en forma de $U$ compuestas por recintos de planta cuadrangular con vanos orientados hacia patios centrales o canchas, acercándose a lo que se ha llamado patrón de rectángulos perimetrales compuestos..$^{10} \mathrm{El}$ sector bajo-oriente está constituido por dos estructuras en U organizadas en torno al explazo central, las cuales se ubican hacia el norte del sector, en tanto, hacia el sur aparece un último conjunto de recintos de traza más irregular aunque siempre con rasgos tardíos.

Entre los 55 recintos la forma dominante de planta es la rectangular en más de un $90 \%$ del conjunto total. Le siguen aquellas de planta cuadrada y con menos de un $2 \%$ aquellas de forma irregular. Las superficies de los recintos varían entre los 1,52 $\mathrm{m}^{2}$ hasta los $62,10 \mathrm{~m}^{2}$, concentrándose entre los 3,96 y $26,98 \mathrm{~m}^{2}$, los que mayoritariamente corresponden a las estructuras que componen los conjuntos de patrón en $\mathrm{U}$.

Otras características arquitectónicas relevantes son el uso de piedra canteada junto con otras semitrabajadas en la construcción de los muros, los cuales mayoritariamente son dobles con relleno, aparejo de aspecto sedimentario, paredes con mortero y/o revoque, la mayoría "a plomo" o a

10 "Conjunto en damero regular preplaneado, formado por una serie de habitaciones inscriptas y adosadas al muro perimetral a partir del cual se construyeron y que, a la vez, rodean un gran espacio central utilizado a veces como un patio, otras como un corral. En manos de los Inca significó la estandarización de un plano urbano rectangular planeado en base a la construcción de un muro perimetral. Este conjunto respondía a la denominación keshua kantja (cancha) (Rowe 1946), sirviendo funcionalmente como lugar de residencia de hombres y camélidos domesticados" (Raffino 1981). Por su parte, Morris, basándose en (Rowe 1946), señala que "la unidad básica de la arquitectura Inca es un edificio rectangular, relativamente pequeño, hecho de piedra con un techo de paja. Estos edificios son similares en muchos aspectos a la forma básica de las casas que todavía se encuentra en los Andes. Aún cuando se los elabora de muchas maneras, y con frecuencia se los constituye en fina mampostería, estas unidades básicas arquitectónicas mantienen su unidad inclusive cuando se encuentran combinadas en grupos para formar complejos arquitectónicos especiales"(1987:28). 
veces levemente inclinados hacia el interior, poyos ${ }^{11}$ exteriores a modo de bancas y, por lo menos en un caso techo a dos aguas.

Cerro Verde fue excavado previo a nuestras investigaciones (Silva $1979 \mathrm{Ms}$ ), lo que permitió sugerir amplias funcionalidades para los sectores descritos. En el sector alto, la estructura compuesta registró cajas emplantilladas que contenían plumas y conchas marinas lo que sería indicativo de un uso ceremonial. El sector bajo-poniente habría servido como "albergue temporal a peregrinos", mientras que en el sector bajo-oriental se habrían localizado las áreas domésticas a juzgar por la mayor depositación de cerámica fragmentada y la evidencia de fogones y huesos quemados (Silva $1979 \mathrm{Ms}$ ).

Nuestras excavaciones se dirigieron a aquellos recintos que pensamos no habrían sido afectados por los trabajos previos, a fin de obtener alguna información estratigráfica a sumar a los antecedentes que obtuvimos de recolección superficial. Se excavaron tres recintos, dos del sector bajo oriental, y uno del sector bajo-poniente. Los resultados de las excavaciones permitieron identificar en el recinto 16 , de planta rectangular y una superficie de $26,98 \mathrm{~m}^{2}$, la presencia de un piso despejado, asociado a un importante explazo, el que de acuerdo a la alfarería superficial recuperada documentaría actividades comunales de consumo de alimentos (Uribe y Carrasco en este volumen). Por el contrario el recinto 46, de planta rectangular y una superficie de $20,70 \mathrm{~m}^{2}$, el cual se integra en el rectángulo perimetral compuesto del sector bajo-oriental, ilustra un área doméstica a juzgar por la presencia de un fogón amparado en el muro y el material cultural recuperado. El depósito indicó la existencia de una ocupación breve pero densa, donde destacan fragmentos de gran tamaño de alfarería poco erosionada, lo que indicaría basura de abandono, entre las cuales se encontraron abundantes representantes del tipo

11 Rowe (1946) describiendo la arquitectura inca señala que algunas pocas casas tenían bancos de piedra o adobe a lo largo de un muro, pese a que la práctica dominante era sentarse encuclillado sobre sus rodillas.
Yavi-La Paya (Uribe y Carrasco en este volumen). Sobre la arquitectura, se logró determinar la existencia de cimientos de piedra cavados en el nivel estéril, técnica poco frecuente en los sitios de la población local donde generalmente son aéreos. El segundo recinto excavado de este sector fue el 30 , de planta rectangular y una superficie de 9,88 $\mathrm{m}^{2}$, que forma parte del conjunto de traza más irregular o norte. Lamentablemente el recinto se encontró completamente excavado, por lo cual las diferencias formales entre este conjunto y el del recinto 46 continúan como interrogantes.

El sector de emplazamiento, el empleo del promontorio rocoso y la relación con cerros de importancia (Hyslop 1990), así como el patrón arquitectónico general y los rasgos particulares, hacen de Cerro Verde un asentamiento fundamental para comprender la presencia incaica en estas regiones. De hecho, gran parte de estos rasgos, son de acuerdo a Raffino (1981) elementos de primer orden del arte constructivo del Tawantinsuyu. En cualquier caso, Cerro Verde es prueba evidente de la presencia directa del Estado inca en estos territorios marginales, con el desarrollo de una arquitectura pública, para la exhibición, que en conjunto con las evidencias del Pukara de Turi, revelan la edificación de espacios y construcciones específicas para la expresión de su poder (Gallardo et al. 1995, Gasparini y Margolies 1980).

Incahuasi-Inca se localiza en la margen sur de la quebrada homónima o sector Laguna Verde, $8 \mathrm{~km}$ al suroeste de Caspana y a una altura de 3.300 m.snm. Se inscribe en otro sistema de cuencas afluentes del río Salado, que desde el sector de los Morros de Cablor desemboca en las cercanías de Chiu-Chiu (Figura 1). Su emplazamiento se encuentra relacionado con un ramal del camino incaico que lo une con Caspana. Desde Incahuasi la red vial se encamina hacia el sur, hacia San Pedro de Atacama, bordeando los pueblos de Machuca y Río Grande (Varela en este volumen).

Como en Cerro Verde, entre las actividades productivas representadas se encuentra la presencia de una mina, con numerosos piques reconocibles, algunos de ellos explotados hasta la fecha. Se suma a lo anterior, la función agrícola del asentamiento, que se evidencia en numerosas andenerías y en el desarrollo de obras agrohidráulicas, desco- 


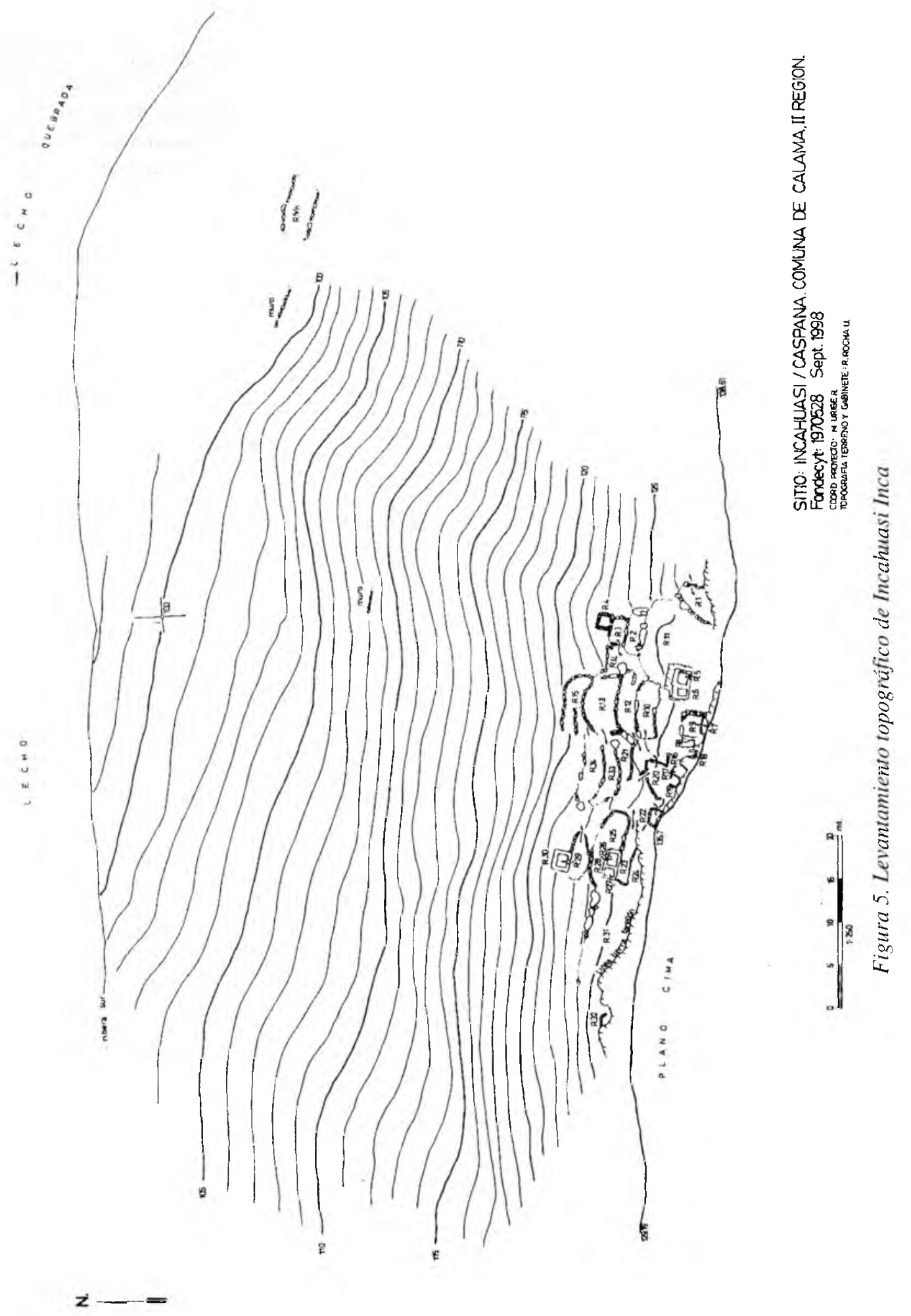


nocidas para otros sectores de la localidad, ${ }^{12}$ las que tienen lugar en un pequeño valle que se forma en la quebrada. Las funciones productivas se acompañan de la construcción de edificaciones para conservar, como son las más de 20 collcas ubicadas a ambos lados de la quebrada, con mayor profusión en la ladera de exposición norte entre el sitio y el pequeño valle, junto a otras en el yacimiento mismo.

Es interesante el hecho que en la quebrada como en el asentamiento se detectan evidencias de una ocupación previa, de tal manera que así como en Cerro Verde y Vega Salada, coincide el interés del Tawantinsuyu con los espacios que habitaron grupos humanos de las Tradiciones Tempranas. En el arte rupestre registrado en el sitio, sobre el farellón rocoso y en ocasiones al interior de las collcas, coexisten paneles adscritos a la ocupación formativa con otros de evidente iconografía incaica.

Incahuasi-Inca se construyó aterrazando el plano inclinado de la quebrada, empleando el área de contacto entre el farellón y el talud. En aquel lugar se dispusieron 34 construcciones entre las que se distinguen estructuras subrectangulares, probables recintos habitacionales o aterrazamientos, y estructuras de planta cuadrangular adosadas a los muros a modo de collcas, y otras también de planta cuadrada, simples y dobles, dispuestas en los extremos del sitio, con aspecto de torreones de patrón constructivo similar a las chullpas. Entre las formas de planta dominan las rectangulares y subrectangulares, seguidas cercanamente por aquellas de formas irregulares. Las superficies se distribuyen entre los 1,36 y los $56,87 \mathrm{~m}^{2}$, concentrándose entre los 1,36 y los $8,28 \mathrm{~m}^{2}$, demostrando la mayor frecuencia en el asentamiento de las

12 En este sector se definen eras de cultivo, canales formados por piedras y pequeños domos, también llamados camellones o rumimokos. En Paniri estos camellones pudieron construirse al menos con el fin de conservar la humedad, distribuir el agua para el riego y regular los factores térmicos, todo esto con el propósito de asegurar las mejores condiciones para el desarrollo del cultivo (Alliende et al. 1993). Se desconoce si su origen es preincaico. Su presencia en Incahuasi, pensamos, tendría lugar en estos momentos, mostrando la incorporación de nuevas técnicas con el objeto de optimizar la producción agrícola. pequeñas estructuras a modo de depósitos o collcas (Figura 5).

Las excavaciones realizadas en Incahuasi aportaron información funcional, a partir de complejos depósitos estratigráficos. El primer recinto excavado fue el 3 del sector Este, de planta trapezoidal y una superficie de $4,55 \mathrm{~m}^{2}$, el cual corresponde a un espacio entre-recintos ubicado ante la estructura 4, esta última de patrón constructivo tipo chullpa, a modo de torreón, que correspondería a una collca por su traza ortogonal. La excavación se ubicó frente y bajo al vano de la estructura 4, donde se identificó la existencia de una grada de acceso. El depósito informa de una matriz cenicienta sin una clara concentración a modo de fogón y alfarería eminentemente doméstica junto con otras de menor frecuencia correspondiente a cerámica revestida rojo. Acerca de la funcionalidad de la estructura 4, en tanto, es indicativo que el depósito exterior sea similar al que hemos detectado en las chullpas de Turi y Talikuna, evidenciando la ejecución de ritos similares vinculados al principio de conservar. Es notable, no obstante lo anterior, la ausencia de restos vegetales en el depósito lo que quizá podría deberse a problemas de conservación.

Otro recinto excavado fue el 13, de planta rectangular y $32,2 \mathrm{~m}^{2}$, localizado en el sector central del asentamiento, donde se observó la presencia de un componente cerámico formativo y un segundo correspondiente a la ocupación de los momentos tardíos. Los antecedentes de los niveles superiores indican podría tratarse de un espacio doméstico (aunque la información no es concluyente), donde la alfarería registrada es eminentemente tardía, como lo indican algunos tiestos revestidos rojos y cerámica Yavi-La Paya.

A continuación, en un pequeño espacio abierto frente a las collcas 8 y 16 , las que se construyeron adosadas al farellón, se realizó otra excavación. Corresponde a los recintos 6 y 18 . El depósito resultó ser sumamente complejo detectándose más de seis estratos. En ellos se observan evidencia del carácter de almacén o bodega de las estructuras, cuestión que habíamos verificado con sondeos previos en el interior de algunas. Se recuperaron notables cantidades de maíz, algarrobo, chañar y otros restos vegetales, además de materiales cul- 
turales misceláneos. En los estratos inferiores se detectó la modificación de la superficie natural de la ladera, por medio de técnicas de terraceo y relleno, y la construcción de un piso artificial el cual utilizó argamasa. Sobre este último se encontraron numerosos ítemes culturales excepcionales como artefactos de madera, astiles, calabazas pirograbadas, cordones vegetales, instrumentos de molienda, metales, plumas, y por supuesto cerámica. Dicha concentración de artefactos y ecofactos fue sellada posteriormente por un evento que incorporó en gran medida la argamasa o revoque de las collcas. Lo interesante es cómo llegó a conformarse aquella depositación tan delicada, infrecuente, y poco organizada. Suponemos que se debió a conductas de saqueo del contenido de las collcas, donde originalmente se encontrarían aquellos objetos, un suceso rápido y violento aunque antiguo, ya que los objetos fueron olvidados y no recuperados.

También se excavó el recinto 23 del sector oeste, de planta rectangular y una superficie de 19,55 $\mathrm{m}^{2}$. Este limita con el farellón rocoso mientras hacia el norte lo hace con dos estructuras con forma de torreón. La depositación es sumamente escasa distinguiéndose cenizas y carbones, por lo que podría tratarse de un espacio en el que se realizaron actividades domésticas.

Para Incahuasi se conocen cinco fechados: 1405 \pm 60 DC (UCTL 1189); $1420 \pm 60$ DC (UCTL 1187); $1435 \pm 60$ DC (UCTL 1186); $1445 \pm 50$ DC (UCTL 718); y $1480 \pm 50$ DC (UCTL 719). Ellos señalan un rango de ocupación muy acotado a momentos finales del Intermedio Tardío (Uribe y Adán 2000).

La densidad en la ocupación del asentamiento, documentada en su depositación cultural, es clara muestra de la anterior situación cronológica. Incahuasi-Inca reproduce, a otra escala y de acuerdo a una función productiva y logística más precisa, el patrón incaico que se sintetiza en Cerro Verde. Si bien están ausentes las grandes canchas, los rectángulos perimetrales compuestos, los muros dobles con relleno y el techo a dos aguas, exhibiendo el patrón arquitectónico cierta cercanía formal con las tradiciones constructivas de la población local, otros rasgos de la ocupación incaica están presentes. Estos, en palabras de un arquitec- to como Agurto (1987:62) expresan un parentesco conceptual que busca "la simplicidad en el diseño, rapidez en la materialización de los mismos y facilidad en su reproducción." Lo cual queda reflejado en el emplazamiento mismo del sitio, en un punto alto que provee de buena visibilidad y permite ser visto, en su orientación hacia el E, en la cercanía a importantes áreas productivas, tanto mineras como agrícolas (¿forraje?), en su asociación a la red vial y al arte rupestre, en la utilización de aplanamiento y la sectorización de las edificaciones. A dichas características se une la planta cuadrangular y de pequeñas dimensiones de una importante proporción de estructuras de aparejo sedimentario y a plomo, piedra canteada, uso de mortero e incluso revoque en algunas, sino en todas.

Emplazado en el río Salado, actual límite norte de la localidad de Caspana y cercano a un camino longitudinal que la une con Toconce, a una distancia de $8 \mathrm{~km}$ de esta ultima localidad, se encuentra la pequeña instalación incaica Vega Salada (Figura 1). Sobre los $3.300 \mathrm{~m} . \mathrm{snm}$, el sitio reitera la relación minería-agricultura que se presenta tanto en Cerro Verde como en Incahuasi-Inca. De hecho, se ubica unos $500 \mathrm{~m}$ aguas arriba del centro minero San Santiago, explotado en períodos subactuales, y desde aquel lugar hasta el asentamiento propiamente tal, se suceden continuamente campos de andenerías.

Particularmente en el caso de las actividades agrícolas, en Vega Salada así como en Incahuasi se observa la intención de ampliar los espacios cultivables, incorporando sectores previamente desestimados por la población local. Este es el caso de la agricultura que se efectúa en esta porción del Salado, la que aprovecha los recursos hídricos de un pequeño manantial que surge a los pies del sitio, el que además, permite el crecimiento de pastos formando una pequeña vega en uso hasta la actualidad.

El sitio fue previamente habitado por poblaciones de las Tradiciones Tempranas del Loa, para luego ser ocupado en el Intermedio Tardío temprano, seguramente como un sistema estanciero como el representado por Mulorojte, tal cual está documentado en sus fechas de $1220 \pm 50$ DC (UCTL 1184). Posteriormente y bien tardíamente, es integrado 


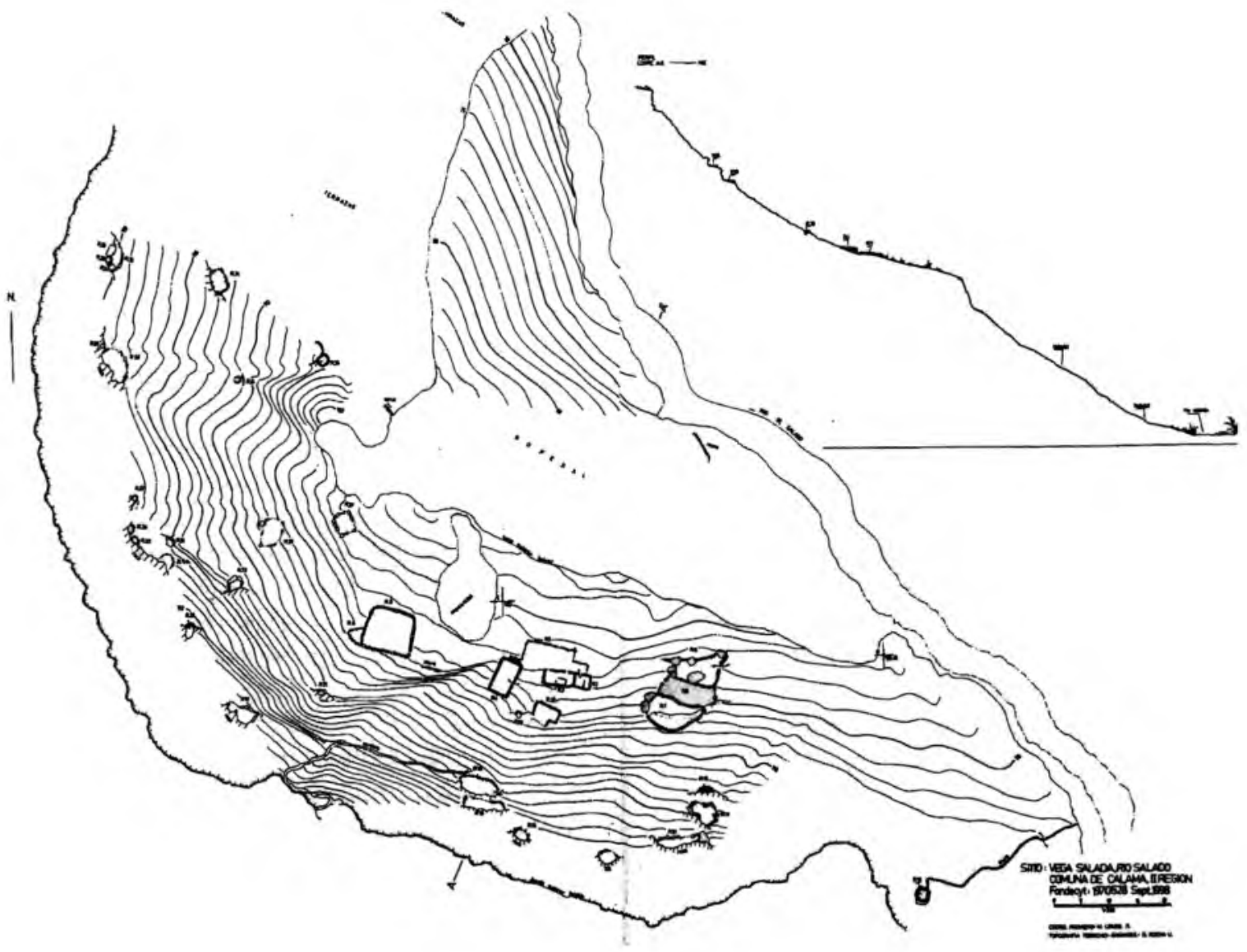

Figura 6. Levantamiento topográfico de Vega Salada

al sistema de instalaciones del Tawantinsuyu, pensamos que con una función eminentemente productiva. Vega Salada, además, se encuentra relacionada a una malla interna de caminos que articula y comunica asentamientos y lugares desde momentos previos a la expansión incaica, aunque seguramente reutilizado por los incas, los cuales coexisten y nutren la red vial mayor que corre más hacia el oeste (Varela en este volumen).

Como en Cerro Verde, el sitio se levanta en un pequeño plano que se desarrolla gracias a un talud bastante suave pero alto de la quebrada en cuyo punto de contacto con el farellón rocoso se adosan varias de las estructuras que componen el sitio, en una suerte de anfiteatro natural. El sitio poco aglutinado se encuentra formado por 36 estructuras que se distribuyen básicamente en dos sectores. En el plano se ubican estructuras rectangulares, subrectangulares e irregulares. Mientras en el punto de quiebre entre el farellón y el talud se localiza una serie de collcas o trojas, mayoritariamente de planta rectangular e irregular, con pequeños vanos, como aquellos de las estructuras tipo chullpa (Figura 6). En los límites del sitio se yerguen recintos a modo de "torreones", siendo de planta cuadrangular y aparejo sedimentario aquellos ubicados hacia el poniente, a diferencia de los que se localizan en el sector oriental, sin visibilidad desde el sector plano del sitio, de planta irregular y aparejo rústico, de más clara filiación a aquellas construcciones definidas como chullpas para Likán (Aldunate y Castro 1981).

En el plano destacan recintos de planta rectangular que conviven con otros irregulares, algunos de ellos usados en la actualidad como corrales. Entre los primeros, se encuentra un conjunto formado 
por $\operatorname{los}$ recintos 2 y 3 , los cuales comparten el muro que los circunda y presentan algunos rasgos menores como la presencia de poyos y cajitas líticas en la superficie. El recinto 4, sin embargo es el que exhibe con mayor claridad los rasgos que lo incluyen dentro del patrón constructivo incaico. Este se edificó perpendicular a la quebrada, presenta un trazado ortogonal, muros dobles con relleno, argamasa, revoque de barro y empleo de piedra canteada. Los paramentos se encuentran combados hacia el interior y se observa una ligera forma trapezoidal en algunos de ellos. Conserva parte de sus cimientos a manera de poyos exteriores y seguramente sostuvo un techo a dos aguas. La excavación de un sector al exterior del recinto, adosado al vértice NE, permitió la identificación de los cimientos y algunos escasos desechos secundarios al amparo de un muro. Un sondeo previo que practicáramos en el interior de la estructura informó de un piso de arcilla despejado. No obstante aquello, tal situación podría estar fuertemente influenciada por el lugar donde se localizó la cuadrícula, correspondiente a un sector de circulación frecuente.

En suma, pensamos que los rasgos arquitectónicos de Vega Salada, las características de su emplazamiento, la vinculación a áreas productivas agrícolas y mineras, la profusión de construcciones para conservar, son expresión de un pequeño enclave incaico en el cual el énfasis no está dado en la exhibición del dominio, aunque de todos modos ello está presente por su visibilidad, sino más bien destacan en él el desarrollo de funciones productivas, fundamentales y necesarias.

\section{A manera de conclusiones}

Acerca de la arquitectura de aldeas y estancias (mirando los poblados locales)

Señalábamos al comenzar que la comprensión de la ocupación humana de la subregión del río Salado durante el Período Intermedio Tardío, puede ser articulada en torno a la noción de "construir para habitar". Con ello nos referimos a un proceso histórico en el cual las poblaciones locales de las tierras altas de Atacama, por medio de la apropiación e incorporación de una tecnología, hacen habitables y productivas las profundas quebradas. También nos referimos a lo que supone toda nue- va tecnología, una forma de habitar, en la que las construcciones permiten vivir y morir, celebrar fiestas, quebrar y denotar el plano, marcar hitos en un espacio propio, igualmente amplio como restringido.

En cuanto a las "construcciones domésticas" observamos dos tipos de asentamientos que habitaron las poblaciones locales, sin perjuicio de lo cual ocasionalmente hayan usado espacios menos intervenidos como aleros o cuevas. Talikuna es representativa del asentamiento conglomerado, a una primera vista ocupado con mayor permanencia, en el que se congregan diversas unidades domésticas. Su construcción es indicativa de un crecimiento espontáneo, no planificado. Se localiza en la mitad del talud de una profunda quebrada, marcando una notoria diferencia con asentamientos de las Tradiciones Tempranas, que se construyeron en las mesas altas aprovechando espacios planos, como ocurrió posteriormente con las instalaciones incaicas. Su emplazamiento establece una directa proximidad con las áreas agrícolas, sin observarse, en la arquitectura, el énfasis ganadero de otros sitios. Mulorojte integra el sistema a modo de estancia, "lugar para estar, lugar donde hacer una estadía", en palabras de Julián Colamar. Su orientación principalmente ganadera, como en las estancias actuales, remite a la misma idea que se observa en Talikuna, es decir habitar el lugar productivo. Durante la prospección que realizáramos de la localidad, reconocimos un importante número de estos sitios, muchos de ellos hasta ahora reutilizados. Sin perjuicio del lugar que se habite la mayor parte del año --la variable temporal aparece como el rasgo definitorio de las cualidades de cada clase de habitación-- ambas categorías de sitios parecen articularse en un sistema, donde la estancia finalmente debe remitir a un asentamiento mayor que congrega y al cual se pertenece.

Sin embargo, no son sólo dos los asentamientos o las clase de sitios, así es probable que Talikuna desde otro nivel de observación haya constituido una estancia agrícola de Caspana. Ciertamente, faltan los datos arqueológicos y preguntas sobre aspectos de la organización social de estas poblaciones para respuestas más concluyentes, sin embargo, es de interés percibir los asentamientos particulares como formando una malla y la nece- 
sidad de considerar que las estrategias de este habitar se desarrollaron en diversos lugares.

Otros lugares donde se habitó por medio de la arquitectura, fue en los espacios para la muerte. De esta manera una segunda modalidad que conforma la noción de "construir para habitar", fueron las "construcciones mortuorias". El sitio de cementerio de mayor importancia durante el período en Caspana, es el de Los Abuelos, levantado en la ladera noreste de la quebrada, tras el Pueblo Viejo, este último muy probablemente asentado sobre un poblado prehispánico. En él, todas las tumbas, en sus diferentes variedades, implican arquitectura, con diferentes trazas y rasgos asociados, pero siempre edificados. Similares a algunas de ellas, particularmente a aquellas bajo bloques rocosos, son algunas pocas que se ubican en la Aldea de Talikuna, sobre el sector doméstico. Por otra parte, se encuentran las estructuras de "patrón constructivo tipo chullpa", complejos torreones de origen altiplánico, las "casitas donde habita la momia" según Ayala (2000), las que han sido interpretadas como lugares donde se practicarían rituales a los antepasados, propuesta basada en los estudios de Likán (Aldunate y Castro 1981), y posteriormente propuesta para Talikuna (Ayala 2000). La localización de las mismas y su relación con los poblados difiere ostensiblemente de un sitio a otro, acotado y separado en Likán, y disperso e integrado en Talikuna. Sus características formales, y de alguna manera su función, las acercan a los depósitos o trojas, "construcciones para conservar". Es probable que algunas de las estructuras tipo chullpa que encontramos en Talikuna correspondan a depósitos, y así los ritos vinculados a la conservación, la riqueza y los antepasados estén fuertemente entrelazados (Aldunate et al. 1981, Uribe et al. 2000).

En suma, la arquitectura local en las tierras altas de Atacama constituye la materialidad que permite a la población original vivir y morir, organizar su espacio, sobreponer las diferentes clases de territorios que se articulan en una geografía. Es en esta geografía donde irrumpe la expansión del Tawantinsuyu.

Construcción de una geografía cultural (mirando las instalaciones incaicas)
La expansión del Tawantinsuyu dejó señales en diversos dominios de la cultura material. La arquitectura en este contexto se constituye más que una señal de algo, en el signo en sí mismo, la expresión del dominio construido. El más transparente sentido de esta arquitectura es la creación de una geografía política y cultural, donde sin perjuicio del lugar que se habite, se participa de una forma jerárquica de organización del paisaje donde se definen centros y caminos, lugares ocultos y otros visibles. El Inca desarrolla una clara estrategia de monumentalidad, una arquitectura pública que congrega a la vez que establece límites y ordena los cuerpos en el espacio. Con todo, el Tawantinsuyu, aquel Estado emergente y expansivo, establece en las tierras altas del Loa, una estrategia "ambigua", dejando libres los asentamientos locales, salvo el más importante (Gallardo et al. 1994), y creando los suyos propios, toda vez que crea cultura en los espacios "silvestres" o "arqueológicos" de las poblaciones locales. Sin embargo, se impone, interviene el paisaje enseñando el uso del sentido más poderoso de las políticas expansivas, la visión. Así la arquitectura incaica se ve, se ve distinta, o no se ve, y su ausencia también muestra.

Observamos en la expresión material del Tawantinsuyu en el Loa un juego entre la monumentalidad/obviedad y la miniaturización/ invisibilidad del dominio. Una materialidad para el dominio debe ser reproducible, distinguible y estilísticamente simple. Sobrerepresenta a fuerza de síntesis. Su expresiva simplicidad permite su expansión, identificarla en paisajes diferentes que luego se asemejarán algo ante los ojos del observador. Aquí como allá. Una materialidad para el dominio amplía los territorios imponiendo hitos monumentales. Esta es la materialidad evidente, es el papel de la arquitectura incaica. Luego, la estrategia del dominio se completa con aquella materialidad mueble (Uribe y Carrasco en este mismo volumen), la miniaturización/invisibilidad del dominio, aquellos pequeños bienes, densos y cotidianos en el espacio doméstico, como los dados incaicos o pichica y aquellos curiosas y significativos nuevos estilos cerámicos tanto en términos tecnológicos como formales, son los que finalmente participan, permiten identificación con la monumentalidad, e integran.

En tal sentido, se observa que la modalidad incaica 
de dominio en la localidad de estudio interviene y afecta una geografía cultural en términos macro por medio de una expresión material significativa para ambos actores involucrados en el arreglo. La monumental arquitectura incaica. Ella debió ser suficientemente expresiva para la población local. Sin embargo, proponemos que ella se completa para los antiguos habitantes de Caspana en la po- sesión de significativos y pequeños objetos en sus espacios domésticos, que portan la densidad de las miniaturas, y que identificarían con aquel obvio poderío edificado, dando mayor fuerza a la estrategia del Tawantinsuyu y a la adopción de esta nueva forma cultural y política por parte de los caspaneños del Intermedio Tardío.

\section{BIBLIOGRAFIA}

\begin{abstract}
ADAN, L.
1995

Diversidad funcional y uso del espacio en el Pukara de Turi. Actas del XIII Congreso Nacional de Arqueología Chilena, Tomo II, pp. 125-134, Antofagasta.

Arqueología de lo cotidiano. Sobre diversidad funcional y uso del espacio en el Pukara de Turi. Memoria para optar al título de Arqueóloga. Departamento de Antropología, Facultad de Ciencias Sociales, Universidad de Chile, Santiago.
\end{abstract}

ADAN, L. y M. URIBE. Cambios en el uso del espacio en los 1995 períodos agroalfareros: Un ejemplo en ecozona de quebradas altas, la localidad de Caspana (Provincia el Loa, II Región). Actas del II Congreso Nacional de Antropología Chilena, pp. 541-555, Colegio de Antropólogos de Chile A.G., Santiago.

1999 El dominio Inca en las quebradas altas altas del Loa Superior: Un acercamiento al pensamiento político andino. Tawantinsuyu (en prensa).

ALdunATE, C. Arqueología del Pukara de Turi. Ac1993 tas del XII Congreso de Arqueología Chilena, Boletín del Museo Regional de la Araucanía, Tomo II, 4:61-78, Temuco.

ALDUNATE, C. y V. CASTRO. Las chullpas de Toconce y 1981 su relación con el poblamiento altiplánico en el Loa Superior. Período Tardío. Tesis para optar al grado de Licenciado en Filosofía con mención en Prehistoria y Arqueología. Facultad de Filosofía, Humanidades y Educación, Universidad de Chile, Santiago.

ALDUNATE, C., J. BERENGUER y V. CASTRO. La fun1981 ción de las chullpas en Likán. Actas del VIII Congreso de Arqueología Chile- na, pp. 129-174, Ediciones Kultrún, Santiago.

ALLIENDE, P., V. CASTRO y R. GAJARDO. Paniri: Un ejem1993 plo de tecnología agrohidraúlica. Actas del XII Congreso Nacional de Arqueología Chilena, Boletín 4:123-128, Museo Regional de la Araucanía, Temuco.

AGURTO, S. Estudio acerca de la construcción, ar1987 quitectura y planeamiento incas. $E$. Mujica (Ed.), Cámara Peruana de la Construcción, Lima, Perú.

AYALA, P. Apropiación y transformación de arqui$2000 \quad$ tectura altiplánica en la región del Loa Superior: La aldea de Talikuna. Actas del XIV Congreso Nacional de Arqueología Chilena. Contribución Arqueológica 5:793-813. Museo Regional de Atacama.

BARON, A.M. Excavación de un cementerio: Sus po1979 tencialidades. Tesis para optar a la Licenciatura en Prehistoria y Arqueología. Departamento de Ciencias Antropológicas y Arqueología, Universidad de Chile, Santiago.

CASTRO, V., F. MALDONADO y M. VASQUEZ. Arquitec1993 tura en el Pukara de Turi. Actas del XII Congreso de Arqueología Chilena, Tomo II: 79-106, Boletín del Museo Regional de la Araucanía, Temuco.

CORNEJO, $\mathrm{L} . \quad \mathrm{El}$ inca en la región del río Loa: Lo 1995 local y lo foráneo. Actas del XIII Congreso Nacional de Arqueología. Tomo I: 203-213. Universidad de Antofagasta, Antofagasta.

CRIADO, F. The visibility of the archaeological re1995 cord and the interpretation of social reality. Interpreting archaeology. Finding meaning in the past, Hodder, 
I., et al. (Eds.), pp. 194-204, Routledge, London \& New York.

GALLARDO, F., M. URIBE y P. AYALA. Arquitectura Inca y 1995 poder en el Pukara de Turi, Norte de Chile. Gaceta Arqueológica Andina VII (24):151-172, INDEA, Lima.

GASPARINI, G. y L. MARGOLIES. Inca architecture. In1980 diana University Press, Bloomington \& London.

GENTILE, M. La pichica en la periferia imperial (San 1997 Luis, siglo XIX). Actas del Congreso de Arqueología Argentina, pp. 217 221, San Rafael.

HYSLOP, J. Inca settlement planning. University 1990 of Texas Press, Austin.

1993 Factors influencing the transmission and distribution of Inca cultural materials throughout Tawantinsuyu. Latin American Horizons, A Symposium at Dumbarton Oaks, pp. 337-356, Dumbarton Oaks Research Library and Collections, Washington D.C.

\section{LE PAIGE, G. Antiguas culturas atacameñas en la cor- 1958 dillera chilena (II parte). Anales de la Universidad Católica de Valparaíso 4 y 5 , Santiago. \\ MORRIS, C. Arquitectura y estructura del espacio en 1987 Huánuco Pampa. Cuadernos del Insti- tuto Nacional de Antropología XIV (2):27-45, Buenos Aires, Argentina.}

NUÑEZ, L. Prospección arqueológica en el norte de 1965 Chile. Estudios Arqueológicos 1:9-35 Antofagasta.
PARKER PEARSON, M.Tombs and territories: Material cul1995 ture and multiple interpretation. Interpreting archaeology. Finding meaning in the past, Hodder, I., et al. (Eds.), pp. 205-209, Routledge, London \& New York.

RAFFINO, R. Los Incas del Kollasuyu. Ramos Ame1981 ricana (Eds.), La Plata, Buenos Aires.

RAFFINO, R., R. ALVIS, L. BALDINI, D. OLIVEIRA y M. 1985 RAVIÑA. Hualfín-El Shingal-Watungasta. Tres casos de urbanización en el N. O. Argentino. Actas del IX Congreso de Arqueología Chilena, pp. 470497, La Serena.

ROWE, J. Cultura incaica durante la conquista es1946 pañola. Handbook of Southamerican Indians 2:183-409.

SILVA, $0 . \quad$ Informe de Avance de las investigacio1979Ms nes del centro ceremonial de Cerro Verde (Talikuna 4), Provincia el Loa. Proyecto $\$ 459$ 791, Universidad de Chile, Santiago.

URIBE M. y L. ADAN. Tiempo y espacio en Atacama: La mi1995 rada desde Caspana. Boletín de la Sociedad Chilena de Arqueología 21:3536 , Santiago.

URIBE, M., V. MANRIQUEZ y L. ADAN. El poder del Inca 2000 en Chile: Aproximaciones a partir de la arqueología de Caspana (Río Loa, desierto de Atacama). Actas del III Congreso Chileno de Antropología, pp. 706-722, Temuco. Lom Ediciones, Santiago. 
